\title{
Speech pathology students' perceptions of workplace-based volunteer placements in a school setting
}

\author{
Marleen Westerveld ${ }^{1}$, Susanne Garvis ${ }^{1}$ \\ m.westerveld@griffith.edu.au; s.garvis@griffith.edu.au \\ ${ }^{1}$ Griffith University
}

\begin{abstract}
Workplace-based learning has long been recognised as crucial in preparing higher education students in allied-health related disciplines for clinical practice. Most of these learning opportunities are embedded in traditional programs and referred to as clinical placements. This study explored the perceptions of university students studying speech pathology who volunteered their services in a school setting. In particular the research aimed to determine what motivated students to undertake volunteer workplace-based learning (for no academic credit), what students learned from being involved in this innovative type of placement, and whether students perceived any benefits in terms of future employability. Student perceptions were gathered using focus group discussions which were subsequently analysed using a content analysis approach to identify key meanings. As expected, students' main motivation to volunteer their service was to add the experience to their resume and thus make them more competitive upon graduation. However, results indicated that the students' learning went beyond their initial expectations of gaining experience in administering assessment tasks. More importantly, the volunteer placement provided the students with clear mastery experiences, leading to improved confidence in their clinical skills and a growth in professional identity. These findings are important for understanding and improving learning experiences within higher education for students who engage in relational work with children and schools.
\end{abstract}

Keywords: Workplace-based learning, learning outcomes, volunteer placements, speech pathology, higher education

\section{Background}

Clinical education plays a pivotal role in preparing students to meet accepted professional standards of practice in speech-language pathology upon graduation. Considering a growing number of university students are studying towards a degree in speech-language pathology, demand for workplace-based learning is high. University programs are increasingly considering the adoption of innovative workplace-based learning models (Sheepway, Lincoln, \& Togher, 2011), with the awareness that student learning outcomes need to be met and that positive student learning experiences are vital. This study explores a non-traditional workplace-based learning model in which students volunteered their services in a school setting. The students involved were studying towards a Master of Speech Pathology degree at Griffith University. The placement facilitated a project that would not have been possible without these students' volunteer assistance.

The volunteer placements participated in a literacy screening clinic of all preparatory students (hereafter known as prep) attending three primary schools in a low socio-economic area, comprised of students from many culturally and linguistically diverse (CALD) 
backgrounds. Prep consists of the first year of schooling in Queensland (state within Australia) with children aged five years. The Australian Early Development Index (AEDI; Australian Government, 2013) results show that 17.8 per cent of children in the school district are considered developmentally vulnerable across two or more areas (http://www.aedi.org.au), which is higher than the national average of 10.8 per cent. Running the screening clinic allowed for detailed evaluation of these children's emergent literacy skills prior to, and following the implementation of a school-wide Tier 1 type intervention within a Response to Intervention Framework (RTI) (Brown-Chidsey \& Steege, 2010). The first tier of this type of intervention demands that all children receive the same evidence-based instruction and that assessment is undertaken to determine which students fail to make expected progress. The clinic resembled a project placement as described by Prigg and Mackenzie (2002) in that the students completed work initiated by a fieldwork site. One of the main drivers of the current project, however, was to help build capacity of the school to more rigorously evaluate the effectiveness of its curriculum delivery, in this instance the implementation of a novel classroom-based small-group intervention program aimed at raising the prep students' early literacy skills (Lennox \& Westerveld, 2013). Under the RTI model students' progress needs to be monitored by regular assessment to determine which students are at risk for learning difficulties and thus may require Tier 2 intervention (www.rti4success.org). Only by speech pathology students volunteering their services, were the schools able to obtain the required staffing resources to assess individual prep students on a range of oral language and literacy-related skills.

Another driver for the current project was the need for additional training of recent graduates in speech pathology (see Rosenberg, Heimler, \& Morote, 2012). In Australia, more than 400 different languages are spoken (Australian Bureau of Statistics, 2010) and more than 20 per cent of Australian preschool-age children grow up speaking more than one language (McLeod, 2011). Considering the high possibility of speech pathologists to encounter clients who speak a language other than English, and who are from a cultural background different from their own, McLeod (2011) rightly argued the importance of cultural and linguistic competence of speech pathologists to work 'sensitively and holistically' with their culturally and linguistically diverse (CALD) clients. Although the Master of Speech Pathology degree program offers clinical placements across the range of practice areas of speech pathology (speech, language, voice, fluency, swallowing, and multimodal communication), there is often little or no opportunity for direct engagement with children from CALD backgrounds. The workplace-based project placement aimed to meet this need by offering extended practice in administering assessment tasks with children from CALD backgrounds.

From a clinical education perspective, some practical and regulatory issues needed to be considered before implementation. These included supervision arrangements, group versus individual placement, and appraisal of student performance. Concerns about non-traditional student placements, such as those involving group supervision, included the amount and quality of the supervision received by the students (Sheepway et al., 2011). Even though the students volunteered for this placement, indirect supervision was provided as mandated by the university. Supervision involved initial training of the students in administering the set battery of assessment tasks by certified practising speech pathologists: 1) students observed their supervisors administering the assessments; 2) students then administered the assessments and received feedback from their peers and supervisor. In addition, daily debriefs were held to discuss progress and administrative or logistical issues and at least one supervisor was on site at all times. Because of the voluntary nature of the placement, students were not formally assessed, nor did they receive formal recognition (i.e. clinical hours towards their degree) for their services. Instead, the students received a certificate of appreciation to include in their professional portfolio.

The current project invited all students who volunteered their services to attend a focus group to address the aim of the research which was to determine the extent to which 
volunteer placements were valued by and contributed to participants' learning. The following research questions were posed:

- What motivated the students to volunteer for this project during their semester break?

- What were their expectations?

- What were the students' perceived learning outcomes?

- Did the placement meet their expectations in terms of experience and learning?

- Should any improvements be made to the placement?

It was anticipated that the key factor motivating the students to volunteer was to add the experience to their resume and thus make them more competitive when applying for positions as new graduates. Obtaining students' views regarding their expectations and learning outcomes would not only determine if this project placement provided a viable learning model, it would also help shape future volunteering experiences for speech pathology students.

\section{Method}

This project received ethical clearance from the university. This allowed all speech pathology students who took part in the volunteering experience to be contacted with an information letter and consent form. The students were post-graduate-entry Master of Speech Pathology students at Griffith University, located on the Gold Coast, Australia. Griffith University recently introduced a Master of Speech Pathology program to meet the growing demand for allied health professionals in Queensland. To gain entry into the program, students were required to have a Bachelor degree (in any subject). The Master of Speech Pathology program is a two-year postgraduate degree program which offers four clinical placement opportunities (one in each semester of study). The degree program addresses all Speech Pathology Range of Practice areas (speech, language, swallowing, voice, stuttering, and multimodal communication) across adults and paediatrics to meet occupational competency at entry level (Speech Pathology Australia, 2011).The program recently obtained accreditation from Speech Pathology Australia, the professional body representing speech pathologists in Australia.

The convenor of one of the speech pathology courses contacted the students in November 2012 , outlining the volunteer project and explaining how the students could be involved. The volunteering experience took place during the summer break; one clinic ran at the beginning of the summer break and involved post-testing of prep children, and one clinic took place at the end of the students' summer break and involved pre-testing of the next prep cohort. Testing involved administration of a battery of emergent literacy assessment tasks, including letter name knowledge, phonological awareness, vocabulary, and story retelling and comprehension. Although the speech pathology students had been informed about these types of tasks during content lectures, few students had had the opportunity to administer the tasks in real world situations.

Of the nine students who participated in the volunteer experience, six were available at a set time to take part in a focus group with a researcher who did not have any affiliation with the students. These students ranged in age from 26 to 54 years, and had completed Bachelor degree programs in Arts, Teaching, Education, Psychology, Psychological Sciences, and Social Sciences. Focus groups are a form of group interviewing that involves a number of people at the same time, with an emphasis being on questions and responses between the researcher and participants. Powell, Single, and Lloyd (1996, p. 499) define a focus group as a group of individuals selected and assembled by researchers to discuss and comment on, from personal experience, the topic that is the subject of the research. The importance of focus groups is that they rely on interaction within the group based on topics that are supplied by the researcher (Morgan, 1997). This allows for the participants to interact about certain beliefs and experiences. In the case of this research, it allowed participants to share 
and interact on the experiences of being involved in volunteering in an authentic placement. The non-affiliated researcher allowed greater opportunity for an honest and open discussion. Students were reassured that all information would be de-identified.

A semi-structured interview approach was used for the focus group that allowed the researcher to explore certain ideas and perceptions as they arose in the conversation. Prompt questions were created to elicit responses based on experience from the volunteering experience. Questions were shared with the participants prior to the interview to allow them to be familiar with the structure and format of the interview. This also allowed the participants to thoughtfully consider their responses to the prompt questions. The focus group lasted for 40 minutes and was audio-taped. Consent was gained through signing of the written consent form and verbal agreement at the start of the interview. Participants were also reminded to be respectful of the views of group members and that information shared was confidential. Participants were informed that all information would be de-identified upon the creation of the transcript from the audio-file. The transcript was returned to participants for verification. This allowed the participants to confirm that what was in the transcript was correct. Once verification had been received from all participants, the transcript was analysed.

Data in the transcript was analysed using an adapted version of Cavana, Delahaye, and Sekaran's (2001) 15 stages of content analysis (Garvis, 2010). The content analysis approach allowed the re-working of themes and ideas to ensure that all data had undergone rigorous analysis. In the writing-up process, data was continually interpreted and revisited to ensure accuracy and consistency. The adapted stages of analysis are listed in Table 1. After undergoing the 15 stages of analysis, key findings were produced that allowed a fuller picture for the study.

\section{Table 1: Adapted Stages of Content Analysis Procedure}

\begin{tabular}{|c|c|}
\hline Stage & Description \\
\hline 1 & $\begin{array}{l}\text { All raw data from interviews were transcribed into single-spaced data and organised } \\
\text { under the interviewee's name. }\end{array}$ \\
\hline 2 & $\begin{array}{l}\text { At the beginning of each paragraph, the interviewee's name was used as the source } \\
\text { code. }\end{array}$ \\
\hline 3 & All data was photocopied to provide more than one original. \\
\hline 4 & All data was securely stored on the computer and in the locked filing cabinet. \\
\hline 5 & All notes and transcripts were read to view emerging themes. \\
\hline 6 & Data was re-read with the coding of themes as they surface. \\
\hline 7 & $\begin{array}{l}\text { Constant comparative analysis occurred as themes were compared. Sub-themes began } \\
\text { to emerge. }\end{array}$ \\
\hline 8 & Themes were given abbreviations and a data index was created. \\
\hline 9 & $\begin{array}{l}\text { Themes were organised using a cut and paste technique. Themes were continually } \\
\text { compared with one another to ensure internal homogeneity (the extent to which the } \\
\text { data in the theme 'dovetail' or hold together in a meaningful way) and external } \\
\text { heterogeneity (the extent to which differences between themes are bold and clear } \\
\text { (Cavana et al., 2001, p. 173). }\end{array}$ \\
\hline 10 & $\begin{array}{l}\text { The open coding phase is now complete. The first pass allowed the researcher to open } \\
\text { up the text, create new concepts and explore themes (Cavana et al., 2001, p.173). }\end{array}$ \\
\hline 11 & Axial coding began with identification of categories of concepts that cluster together. \\
\hline 12 & $\begin{array}{l}\text { After reviewing each category, rules for inclusion were established about including or } \\
\text { not including subsequent data. }\end{array}$ \\
\hline
\end{tabular}



sub themes was compared and contrasted.

14 Mapping across categories to investigate relationships occurred to draw a fuller picture for the study.

15 All results were written up through an interactive process, with data continually revisited and checked to support various arguments.

\section{Findings}

\section{Motivation for volunteering}

The participants stated that their motivation for volunteering was based on the appeal of working with school-aged children and, in particular, the opportunity to gain skills in implementing a variety of assessments to a range of school-aged children was valued. The participants suggested that they were able to really understand how different assessment tools worked and what changes needed to be made when they dealt with different children.

For a small group of participants, it also confirmed whether they would like to work in paediatrics once they finished their university qualification. While the participants had just undertaken a practicum in a paediatric setting, they reported that they had not had time to develop relationships with individuals. One participant commented that the previous experience in paediatrics was too short and made her feel nervous because she rarely saw the same children twice for a session. In this volunteering experience, the participants were motivated to learn about the dynamics of being a paediatric speech pathologist in one particular type of school context as opposed to travelling across a variety of schooling contexts. After the experience, three participants confirmed they would like to work in paediatrics, one participant did not, and one participant was still undecided. One student commented:

For me, the appeal was the school-aged children because l've been doing my behaviour therapy with early interventions at two to six. I had a small window of experience in first semester at a school and I really liked it, so I thought, well, let's get back into the school. It could be a career opportunity one day down the track (Respondent 3).

\section{Expectations}

Participants were asked to comment on whether their expectations had been met. All participants commented that the experience had exceeded their expectations. They suggested this was because they had a supportive supervisor and speech pathologists who were able to support their learning and needs. The participants suggested they were treated as equals, developing an identity as a practising speech pathologist as opposed to being a student under supervision. One participant commented:

I think it exceeded mine in terms of the level of support that we got. The supervisor there from the school, the speech pathologist at the school was very, very supportive and she was very accommodating.

The participants also stated they were valued as part of a wider project that was aimed at improving the oral language development of young children. The participants commented they were making an important contribution to the lives of young children and felt good about this factor. They considered involvement in the project valuable for not only their own learning but also for the greater good of the young children.

The participants valued the importance of receiving a certificate for their portfolio at the end of the program. They believed that being able to draw on 'real life' experience when seeking 
employment made them more employable than others in the speech pathology program who had not undertaken this volunteering program. The participants suggested that an employer would be looking for a range of practical experiences that they could now demonstrate. For example, one participant commented:

If a girl went to apply for a job in a school, I think the employer would go, $\mathrm{hmm}$, they've done some experience, they haven't, so from that perspective, I think it's really important (Respondent 1).

\section{Perceived learning outcomes}

The participants were also asked to comment on what they had learned from the experience. Many participants commented on the value of learning about the school culture, including the different roles of teachers, principals, and administration. One participant stated:

There was that side of it, but there was also the side of it that showed that some teachers were a bit more receptive than others to working with the speech pathologist, whereas others seemed to see it as a little bit of a challenge to their own knowledge because this aspect of literacy crosses over both professional boundaries, I suppose. That collaboration is - you can get so much further ahead if you work in that way, but not everybody seems willing to do that (Respondent 2).

This was important to the participants as it allowed them to experience the importance of communication between all team members to ensure consistency for children's learning.

Participants also stated that they had learnt important insights into children's lives and learning. There was general agreement that the experience had allowed them to observe the differing abilities of the children and develop a greater understanding about the home life of the child. The participants were able to experiment with their own communication styles and engagement styles to cater for a diverse range of children. For example, one participant commented:

With the more challenging children or the ones that would flat out not respond, you'd have to get creative in ways to inviting them to respond while still using the constraints; using the prompts that were given but I would pause the recorder and bring out a toy if I needed to for the re-tell if they were flat out refusing, and often that would bring them back so it's just finding those things that you need to do in that situation.

This also included developing an understanding of children who came from a range of diverse backgrounds including English as second language and different socio-economic status. One participant commented:

I found that some of them said things that were a bit eye-opening for me, and probably not something I would have experienced. I don't have children of my own, so I don't have a lot of experience with children. For me, it's always a bit of a challenge to go into something like that, but I really liked it so it really has shifted my view but also that whole socioeconomic perspective and different culture. Some of the things those kids said really were quite surprising to me (Respondent 4).

From this experience the participants gained a greater understanding of having staff in a school who speak a language other than English to directly engage with the children. A number of participants commented on the benefits of having a teacher aide who spoke other languages to directly assist the children in the oral language development. 
Peer learning emerged as an important learning outcome for the participants. They were able to learn from one another and reflect on each other's capabilities. This allowed more open dialogue about what they were doing, again creating a supportive and collaborative environment in which to work.

Participants also suggested that they gained personal growth and confidence from the experience. They commented that they were able to learn from a range of mistakes they had made initially in the assessment of the children. The participants suggested that as the volunteering experience was not formally assessed by a supervising speech pathologist, they were able to relax and concentrate on the task. They valued the feedback that was given to them after each session and viewed the speech pathologists more as mentors than assessors. One participant commented:

For me, it made me feel more relaxed about what I was doing. I knew that I was just going to give it my best shot (Respondent 3).

The final learning outcome was based around seeing the development of the children's oral language. As some of the participants undertook a pre and post-test assessment of the individual children, they were able to see first-hand the influence of a speech pathologist in helping a child's development be extended. Even in cases where the observed improvement was minimal, the participants realised the importance of regular engagement with young children to support the development of oral language.

\section{Improvements}

While the volunteering was a valuable experience for participants, some improvements for future programs were suggested. The first was an economic consideration with participants commenting on the costs of undertaking the volunteering as a university student. In particular all participants commented on the cost of travel to get to the school that was not easily accessible by public transport. The participants suggested it would be helpful to consider a more cost-effective way to travel to the schools.

The second concern of participants was for a better communication strategy with the generalist classroom teachers about what they were doing. Some participants suggested the teachers were unaware of the assessments that were being undertaken and the importance of sharing information about the oral language development of children. One participant commented:

I just wonder how much the teachers were actually told what was going on because the few that I talked to, they were saying, what are you doing? I had thought, maybe naively, that they would be notified that this is what's happening (Respondent 4).

This response raises awareness of the importance of belonging during a placement. For students to feel as though they belong and are accepted within a context, it is important that all professionals are aware of their role, including those professionals (such as teachers) who may not previously have worked with a student speech pathologist in a schooling context.

The final recommendation was based around developing a better understanding of the bigger research project in which the participants were involved and knowing the results of the overall progress of the children. The participants would have liked to have more information about the intervention program that the speech pathologists had delivered to also improve their own understanding about intervention programs.

Overall the participants agreed unanimously that they would undertake the volunteering experience again. Some participants suggested it was not easy to volunteer in organisations 
and suggested that this was a good learning experience organised by the university. The participants also suggested they would recommend the experience to other speech pathology students.

\section{Discussion}

This project investigated speech pathology students' perspectives regarding a volunteering experience that was organised by the university during the summer break. The Master of Speech Pathology students volunteered to participate in a literacy screening clinic for 5-yearold prep students attending primary schools in a low socio-economic and culturally and linguistically diverse community. Their involvement consisted of administering a battery of assessment tasks related to young children's emergent literacy skills. The focus of the research project was to determine what motivated the students to participate, what the perceived learning outcomes were, and how the experience could be improved in the future. These findings would potentially help shape future workplace-based volunteering experiences for speech pathology students.

As expected, the students' main motivation for volunteering was to help them develop confidence, build their clinical speech pathology skills and ultimately help them become more competitive when applying for positions following graduation. Another motivation, however, was that the volunteer placement gave some students the opportunity to better understand the role of a speech pathologist in a school setting, thus providing a sound basis for making career choices following graduation. As mentioned previously, although the Master of Speech Pathology degree program addresses all Speech Pathology Range of Practice areas (speech, language, swallowing, voice, stuttering, and multimodal communication) across adults and paediatrics to meet occupational competency at entry level (Speech Pathology Australia, 2011), the degree program cannot offer clinical placements across the wide range of settings in which speech pathologists typically practice. Providing the students with this optional volunteering experience therefore indirectly adds value to the degree program while at the same time enhancing their employability.

Regarding the question of learning outcomes, it is evident from the student responses that their learning clearly went beyond their initial expectations of gaining experience in administering emergent literacy tests, and included a better understanding about the school culture as well as an enhanced awareness of the practical implications of working with prep students from low socio-economic and/or culturally and linguistically diversity (CALD) backgrounds. The experience highlighted the need for the students to be flexible in their working style, and provided them with a real appreciation of working with school staff who spoke languages other than English. Considering the high number of CALD children in Australia (McLeod, 2011), this placement therefore fulfilled the intention of the volunteering placement in this particular educational setting.

A further positive finding was that the volunteering experience exceeded all students' expectations. The students clearly valued the model of supervision and the advantage of peer learning. Advantages of peer learning in more traditional placement models include active learning, clinical independence, and a sense of ownership of the learning experience (see Lekkas et al., 2007). Perhaps more importantly, however, the speech pathology students reported that the experience contributed to the development of their professional identity as a speech pathologist. As explained by Godsey (2011), development of professional identity is 'a critical and formative process' that starts during the students' education training program and continues 'throughout a lifetime of practice' (p.1). Considering the speech pathology students were halfway through their postgraduate degree program, the volunteering experience was clearly perceived by the students as being beneficial to their learning, and provided a valuable foundation for their second and final years of studies and further clinical placements. 
The final question to the speech pathology students related to possible improvements to the volunteering placement. Although some of the suggestions were of a practical nature (i.e. cost of transport), the most significant finding related to the need to improve overall communication by ensuring all school staff were fully aware of the research project and the associated assessment schedule. The speech pathology students also showed a keen interest in learning more about the school-wide Tier 1 intervention plan.

One of the limitations of this type of research is that findings cannot be generalised beyond the participants to a larger population. The results may not generalise to undergraduate speech pathology students, who are generally younger and may have less life experience (see Martin, Wilson, Liem \& Ginns, 2013). However, the study does provide important insights about the value of a volunteering learning experience to enhance individual learning outcomes and personal growth, and allow a greater understanding of the role of a speech pathologist in a school setting, both critical to a first professional appointment.

While the study did not attempt to compare the perceived outcomes of the volunteer placement with the experiences of more traditional placements, this is an area of interest for future research. Despite the limitations, the study does suggest that students are willing to engage in learning which enhances their professional skills and understanding even though it does not carry academic credit points.

\section{Conclusion}

The results from this study not only support the importance of providing speech pathology students with opportunities to practise their skills in a real world situation, they also demonstrate the need to formally evaluate these types of work-place based initiatives. The volunteering project provided the students with clear mastery experiences as illustrated by the students' reports of improved confidence in their clinical skills and their growth in professional identity. Positive beliefs of self-efficacy are important, as professionals with higher self-efficacy are more likely to be successful and effective in their clinical practice.

\section{Acknowledgement}

Our heartfelt thanks go to the speech pathology students for generously volunteering their time to support the research project. 


\section{References}

Australian Bureau of Statistics. (2010). Yearbook Australia 2009-2010. Retrieved from http://www.abs.gov.au

Brown-Chidsey, R. \& Steege, M. (2010). Response to intervention: Principles and strategies for effective practice (2nd ed.). New York: Guilford Press.

Cavana, Y. R., Delahaye, L. B. \& Sekaran, U. (2001). Applied business research: Qualitative and quantitative methods. Sydney: Wiley.

Garvis, S. (2010). An investigation of beginning teacher self-efficacy for the arts in the middle years of schooling (years four to nine). (Unpublished doctoral dissertation.) The University of Queensland.

Godsey, S. R. (2011). Student perceptions of professional identity and cultural competence. (Unpublished Doctoral Dissertation.) Faculty of the Graduate School, University of Minnesota.

Lekkas, P. Larsen, T. Kumar, S., Grimmer, K., Nyland, L., Chipchase, L., ...Finch, J. (2007). No model of clinical education for physiotherapy students is superior to another: A systematic review. Australian Journal of Physiotherapy, 53(1), 19-28.

Lennox, M. \& Westerveld, M. F. (in review). Enhancing emergent literacy performance of Australian students from disadvantaged backgrounds in their first year of school: A preliminary investigation.

Martin, A. J., Wilson, R., Liem, G. A. \& Ginns, P. (2013). Academic momentum at university/college: Exploring the roles of prior learning, life experience, and ongoing performance in academic achievement across time. The Journal of Higher Education, 84(5), 640-674.

McLeod, S. (2011). Cultural and linguistic diversity in Australian 4- to 5-year-old children and their parents. ACQuiring Knowledge in Speech, Language and Hearing, 13(3), 112119.

Morgan, D. L. (1997). Focus groups as qualitative research. London: Sage.

Powell, R. A., Single, H. M. \& Lloyd, K. R. (1996). Focus groups in mental health research: Enhancing the validity of user and provider questionnaires. International Journal of Social Psychology, 42(3), 193-206.

Prigg, A. \& Mackenzie, L. (2002). Project placements for undergraduate occupational therapy students: Design, implementation and evaluation. Occupational Therapy International, 9(3), 210-236.

Rosenberg, S., Heimler, R. \& Morote, E.-S. (2012). Basic employability skills: A triangular design approach. Education + Training, 54(1), 7-20.

Sheepway, L., Lincoln, M. \& Togher, L. (2011). An international study of clinical education practices in speech-language pathology. International Journal of Speech-Language Pathology, 13(2), 174-185.

Speech Pathology Australia. (2011). Competency-based occupational standards for speech pathologists (CBOSS) entry level. Melbourne: Speech Pathology Association Australia Ltd. 